\section{RMD Open}

Rheumatic \& Musculoskeletal Diseases

\title{
Immunomodulatory therapies for the treatment of SARS-CoV-2 infection: an update of the systematic literature review to inform EULAR points to consider
}

To cite: Alunno A

Najm A, Mariette X, et al. Immunomodulatory therapies for the treatment of SARSCoV-2 infection: an update of the systematic literature review to inform EULAR points to consider. RMD Open 2021;7:e001899. doi:10.1136/ rmdopen-2021-001899

- Additional supplemental material is published online only. To view, please visit the journal online (http://dx.doi.org/10. 1136/rmdopen-2021-001899).

AA and AN contributed equally.

$A A$ and $A N$ are joint first authors

Received 26 August 2021 Accepted 12 0ctober 2021

Check for updates

(C) Author(s) (or their employer(s)) 2021. Re-use permitted under CC BY-NC. No commercial re-use. See rights and permissions. Published by BMJ.

For numbered affiliations see end of article.

Correspondence to

Dr Alessia Alunno;

alessia.alunno82@gmail.com

\section{ABSTRACT}

Objective To update the EULAR 2020 systematic literature review (SLR) on efficacy and safety of immunomodulatory agents in SARS-CoV-2 infection.

Methods As part of a EULAR taskforce, a systematic literature search update was conducted from 11 December 2020 to 14 July 2021. Two reviewers independently identified eligible studies and extracted data on efficacy and safety of immunomodulatory agents used therapeutically in SARS-CoV-2 infection at any stage of disease. The risk of bias (RoB) was assessed with validated tools.

Results Of the 26959 records, 520 articles were eligible for inclusion. Studies were mainly at high or unclear RoB. New randomised controlled trials (RCTs) on tocilizumab clarified its benefit in patients with severe and critical COVID-19, mainly if associated with glucocorticoids. There are emergent data on the usefulness of baricitinib and tofacitinib in severe COVID-19. Other therapeutic strategies such as the use of convalescent plasma and anti-SARSCoV-2 monoclonal antibodies showed efficacy in subjects not mounting normal anti-SARS-CoV-2 antibody responses. Conclusion This new SLR confirms that some immunomodulators (tocilizumab and JAK inhibitors) have a role for treating severe and critical COVID-19. Although better evidence is available compared with the previous SLR, the need of RCT with combination therapy (glucocorticoids+anti-cytokines) versus monotherapy with glucocorticoids still remains alongside the need for standardisation of inclusion criteria and outcomes to ultimately improve the care and prognosis of affected people. This SLR informed the 2021 update of the EULAR points to consider on the use of immunomodulatory therapies in COVID-19.

\section{INTRODUCTION}

The SARS-CoV-2 pandemic has challenged the global healthcare system. Severe COVID-19 pneumonia is associated with

\section{Key messages}

What is already known about this subject?

- Several compounds with immunomodulatory activity have been tested in patients with SARS-CoV-2 infection at various stages of the disease.

- Randomised controlled trials (RCTs) are available only for a few immunomodulatory compounds/strategies, sometimes with conflicting results, and mostly for moderate to severe/critical COVID-19.

What does this study add?

- By updating the previous systematic literature review (SLR), all the new RCTs published up until July 2021 were collected. The efficacy of glucocorticoids and tocilizumab in severe and critical COVID-19 was clarified and potentially new promising therapeutic approaches were described.

- There are emergent data on the usefulness of baricitinib and tofacitinib in severe COVID-19, mainly if associated with glucocorticoids.

- Other therapeutic strategies such as the use of convalescent plasma and anti-SARS-CoV-2 monoclonal antibodies seem to be useful only in selected subgroups of patients.

How might this impact on clinical practice or further developments?

- This SLR informed the 2021 update of the EULAR points to consider for the use of immunomodulatory therapy in COVID-19.

inflammation and immunothrombosis that may be treatable with immunomodulatory therapies but optimal treatment and timing is incompletely understood. Our previous systematic literature review (SLR) ${ }^{1}$ noted that despite the extremely large number of available studies, randomised controlled trials (RCTs) were few and most articles were of 
lower level of evidence and at high risk of bias (RoB). Data on efficacy (or lack thereof) of some compounds such as hydroxychloroquine (HCQ) were consistent across studies; however, for other drugs, such as tocilizumab (TCZ), both positive and negative results were reported without a strong signal in either direction. ${ }^{1}$ Furthermore, data emerging from the 'grey literature', either in full as preprints or in part via press releases, added a layer of complexity underscoring the evolving nature of COVID-19 where contradictory findings were often reported.

Since new studies are continuously published, overarching institutions regularly update their recommendations for the management of COVID-19. ${ }^{23}$ Similarly, we conducted an update of our SLR in order to inform the 2021 update of the EULAR points to consider for the use of immunomodulatory therapy in COVID-19.

\section{METHODS}

\section{Search methodology}

Based on the same research questions of the original SLR and using the same systematic search strategy, ${ }^{1}$ a search was performed in MEDLINE, Embase, The Cochrane Database of Systematic Reviews, CENTRAL and CINAHL. The search was conducted from 11 December 2020 (cutoff date of the previous SLR) to 14 July 2021. The PubMed Similar Articles tool was also used, and a crosscheck of the key scientific journals in general medicine and immunology was performed. Non-peer-reviewed literature was excluded given this SLR aimed at informing recommendations. However, given the rapid evolution of knowledge on COVID-19 treatment, a parallel hand search of 'grey literature', restricted to RCT not yet published in peer-reviewed journals but accessible in press releases or in extenso in preprint repositories, was performed. These not yet published RCTs are presented separately and were not used to inform the points to consider. We also conducted a new search to explore the efficacy and safety of anti-SARS-CoV-2 monoclonal antibodies (mAbs) in infected subjects up to 14 July 2021 (online supplemental text 1).

\section{Study selection, data collection and assessment of RoB}

Original research articles of any study design, published in English, in peer-reviewed journals, addressing adults with proven SARS-CoV-2 infection treated with one or more immunomodulatory agent or with anti-SARS-CoV-2 mAbs, were eligible. Two reviewers (AA and AN) independently assessed titles and abstracts according to the predetermined eligibility criteria, followed by full-text review. Discrepancies were resolved by discussion and the task force methodologist (PMM) was consulted in the case of uncertainties. Data on patient characteristics, investigated drug and administration scheme, and comparators and outcomes were extracted, as in the previous SLR. Whenever possible, risk ratios (RRs) and corresponding CIs were calculated. The RoB was assessed using validated tools.

\section{RESULTS}

Of the 26959 records yielded by the search on immunomodulatory therapies, 711 were selected for full-text review and 3 additional articles were identified by handsearch. Of these, 520 articles on 33 therapeutic strategies met the inclusion criteria (online supplemental tables 1 and 2). Robust evidence was mostly available for moderate-to-severe/critical COVID-19.

Of the 275 records yielded by the search on anti-SARSCoV-2 mAbs, 39 were selected for full-text review and 19 met the inclusion criteria (online supplemental table 3 ). The best evidence available for each compound is shown.

\section{RCT data in patients with moderate to severe/critical COVID-19}

A total of 37 RCTs, all at high or unclear RoB, evaluating 14 therapeutic approaches in severe/critical COVID-19 were retrieved by the SLR (online supplemental table 4).

\section{Antimalarials}

Eleven new RCTs were retrieved by the SLR search update, adding to the existing eight RCTs on HCQ included in the previous SLR. Out of these 11 new studies, 4 have been stopped early for futility, ${ }^{4-7} 2$ have been stopped for harmful effects of one or several compounds in the intervention arms, ${ }^{89}$ and 1 is underpowered, ${ }^{10}$ hence the results are not described in this manuscript. Out of the six studies that included patients with moderate to severe COVID-19, one compared HCQ to chloroquine or ivermectine showing no efficacy on death, progression to invasive mechanical ventilation (IMV) or admission to intensive care unit (ICU) at day $90 .{ }^{11}$ The second study explored the efficacy and safety of adding either HCQ lopinavir-ritonavir or a combination of the two to standard of care (SOC) in critically ill patients. ${ }^{12}$ One of the major findings of this trial is a significant reduction of survival in all three intervention arms compared with SOC (OR $0.65,95 \%$ CI 0.45 to 0.95 ; OR $0.56,95 \%$ CI 0.30 to 0.89 ; and OR $0.36,95 \%$ CI 0.17 to 0.73 , respectively), suggesting a harmful role of lopinavir-ritonavir and HCQ (tables 1 and 2).

\section{Glucocorticoids}

Three new RCTs on glucocorticoids (GCs) were retrieved by the SLR update. Unfortunately, all three studies failed to recruit the target number of subjects allowing the trials to be sufficiently powered and therefore were interrupted early and no conclusion could be drawn from the results. ${ }^{13-15}$

\section{IL-6R inhibitors}

The search update retrieved seven new RCTs on tocilizumab (TCZ) ${ }^{16-22}$ including COVACTA, ${ }^{18}$ REMAP-CAP, ${ }^{19}$ RECOVERY, ${ }^{20}$ EMPACTA $^{22}$ and the post hoc analysis of the CORIMUNO-TOCI- 1 trial at day 90 on the subgroup 


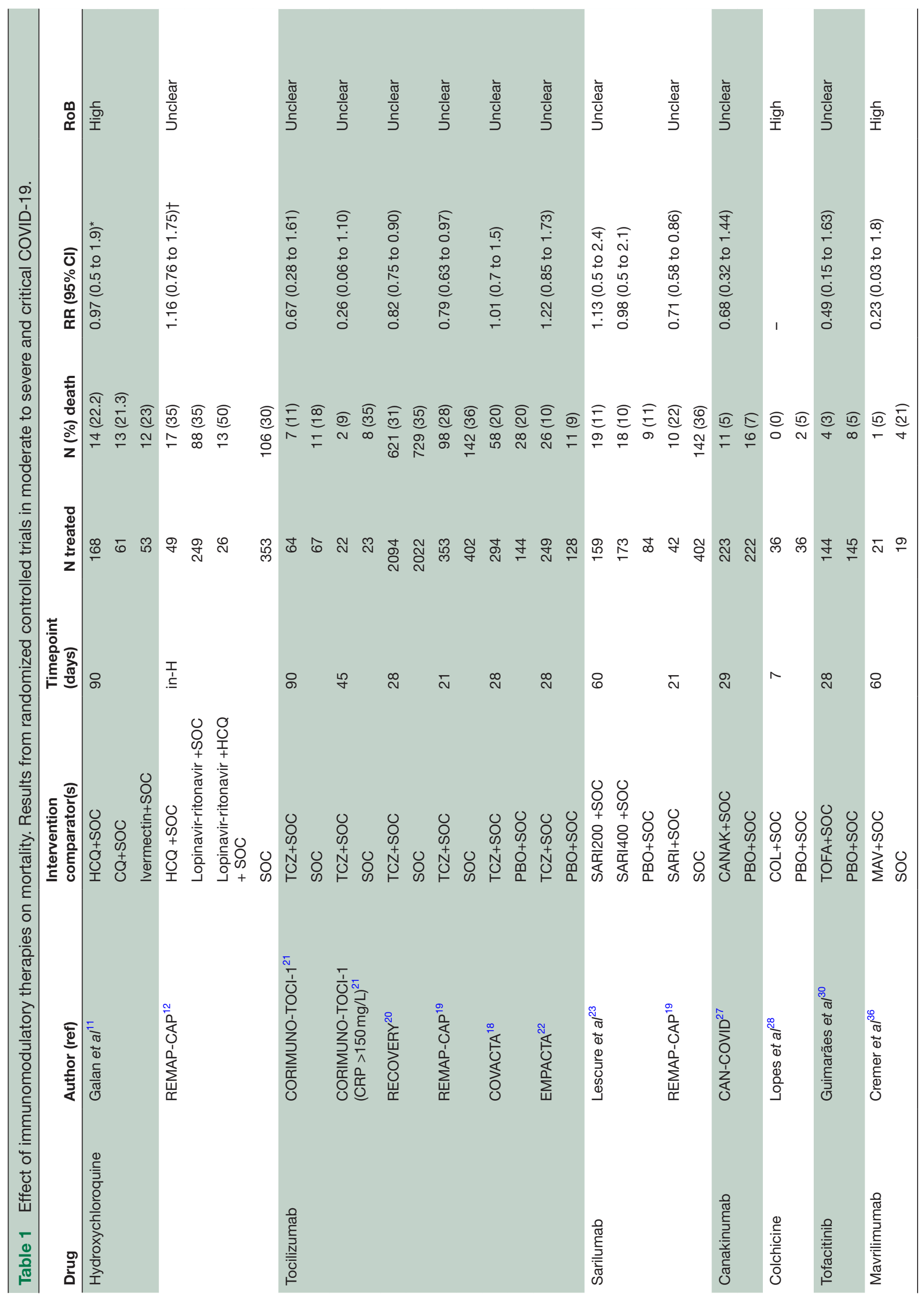




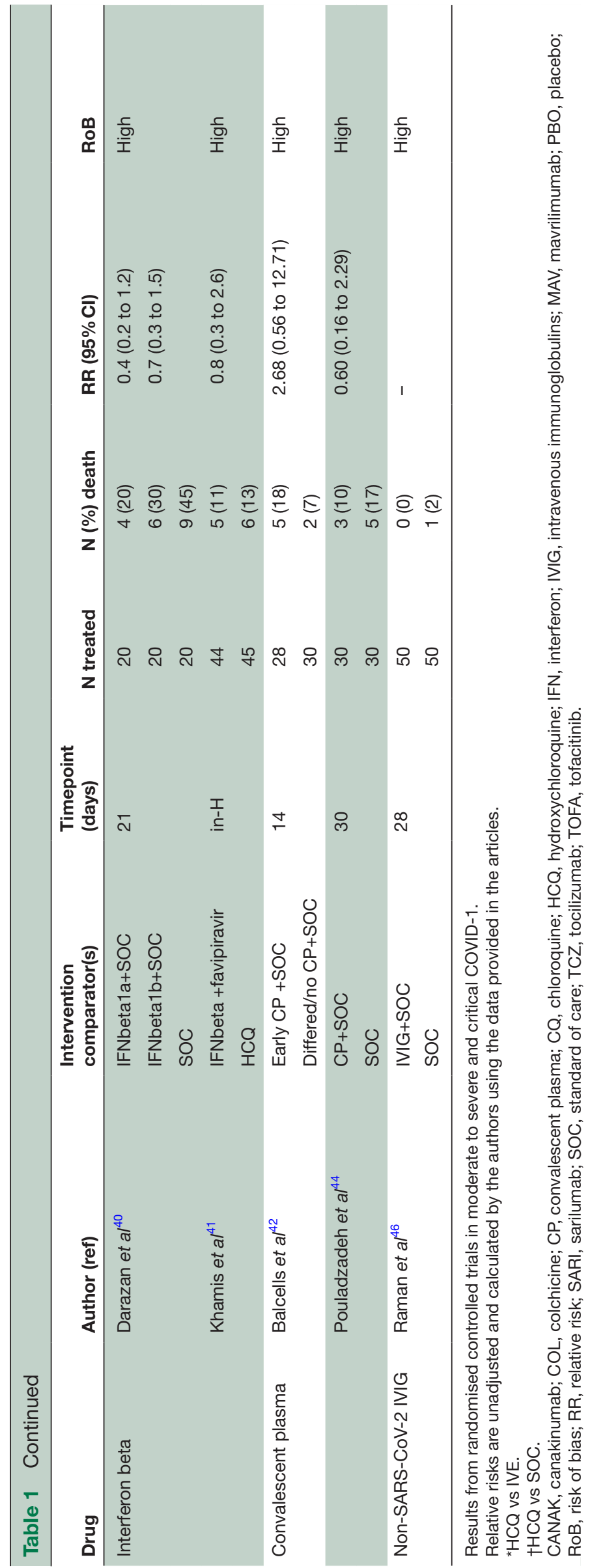

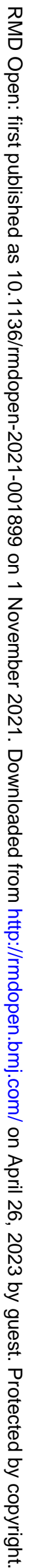


Table 2 Effect of immunomodulatory therapies on ventilation. Results from randomized controlled trials in moderate to severe and critical COVID-19.

\begin{tabular}{|c|c|c|c|c|c|c|}
\hline Drug & Author (ref) & $\begin{array}{l}\text { Intervention } \\
\text { comparator(s) }\end{array}$ & $\begin{array}{l}\text { Timepoint } \\
\text { (days) }\end{array}$ & $\mathbf{N}$ treated & Results & RoB \\
\hline \multirow[t]{3}{*}{ Hydroxychloroquine } & \multirow[t]{3}{*}{ Galan et al ${ }^{11}$} & $\mathrm{HCQ}+\mathrm{SOC}$ & \multirow[t]{3}{*}{90} & 168 & \multirow{3}{*}{$\begin{array}{l}\text { Patients requiring IMV } \\
13(21) \\
12(21) \\
13(23) \\
\text { HCQ vs IVE RR }(95 \% \text { CI) } 0.83(0.4 \\
\text { to } 1.6)\end{array}$} & \multirow[t]{3}{*}{ High } \\
\hline & & $\mathrm{CQ}+\mathrm{SOC}$ & & 61 & & \\
\hline & & Ivermectin+SOC & & 53 & & \\
\hline \multirow[t]{14}{*}{ Tocilizumab } & \multirow[t]{4}{*}{ Mariette et $a l^{21}$} & $\mathrm{TCZ}+\mathrm{SOC}$ & \multirow[t]{4}{*}{90} & 64 & \multirow{4}{*}{$\begin{array}{l}\text { IMV or death, subgroup CRP>15mg/ } \\
\text { dL, } \\
18 \% \\
57 \% \\
\mathrm{HR}(95 \% \mathrm{Cl}) 0.18 \text { (0.06 to } 0.59)\end{array}$} & \multirow[t]{4}{*}{ Unclear } \\
\hline & & SOC & & 67 & & \\
\hline & & & & & & \\
\hline & & & & & & \\
\hline & \multirow[t]{4}{*}{ RECOVERY ${ }^{20}$} & $\mathrm{TCZ}+\mathrm{SOC}$ & \multirow[t]{4}{*}{28} & 2094 & \multirow{4}{*}{$\begin{array}{l}\text { Non-IMV subgroup progression to } \\
\text { IMV or death } \\
35 \% \\
42 \% \\
\text { RR }(95 \% \mathrm{Cl}) 0.84 ; 0.77 \text { to } 0.92\end{array}$} & \multirow[t]{4}{*}{ Unclear } \\
\hline & & SOC & & 2022 & & \\
\hline & & & & & & \\
\hline & & & & & & \\
\hline & \multirow[t]{2}{*}{ REMAP-CAP ${ }^{19}$} & $\mathrm{TCZ}+\mathrm{SOC}$ & \multirow[t]{2}{*}{21} & 353 & \multirow{2}{*}{$\begin{array}{l}\text { CV and respiratory organ support- } \\
\text { free days OR ( } 95 \% \text { credible interval) } \\
1.64 \text { ( } 1.25 \text { to } 2.14)\end{array}$} & \multirow[t]{2}{*}{ Unclear } \\
\hline & & SOC & & 402 & & \\
\hline & \multirow[t]{2}{*}{ COVACTA $^{18}$} & $\mathrm{TCZ}+\mathrm{SOC}$ & \multirow[t]{2}{*}{28} & 294 & \multirow{2}{*}{$\begin{array}{l}\text { Clinical status on } 7 \text {-point ordinal } \\
\text { scale } \\
-1.0 ; 95 \% \mathrm{Cl}-2.5 \text { to } 0 ; p=0.31\end{array}$} & \multirow[t]{2}{*}{ Unclear } \\
\hline & & $\mathrm{PBO}+\mathrm{SOC}$ & & 144 & & \\
\hline & \multirow[t]{2}{*}{ EMPACTA $^{22}$} & $\mathrm{TCZ}+\mathrm{SOC}$ & \multirow[t]{2}{*}{28} & 249 & \multirow{2}{*}{$\begin{array}{l}\text { Progression to IMV or death: } \\
\text { HR }(95 \% \mathrm{Cl}) 0.56 \text { (0.33 to } 0.97)\end{array}$} & Unclear \\
\hline & & $\mathrm{PBO}+\mathrm{SOC}$ & & 128 & & \\
\hline Sarilumab & Lescure et $a^{23}$ & SARI $200+$ SOC & 60 & 159 & Need of NIV/IMV & Unclear \\
\hline & & SARI $400+$ SOC & & 173 & $\begin{array}{l}26(20) ; \operatorname{RR}(95 \% \mathrm{Cl}) 1.06(0.6 \text { to } 1.9) ; \\
33(30) ; \operatorname{RR}(95 \% \mathrm{Cl}) 1.2(0.7 \text { to } 2.2)\end{array}$ & \\
\hline & & $\mathrm{PBO}+\mathrm{SOC}$ & & 84 & 13 (19) & \\
\hline & REMAP-CAP ${ }^{19}$ & SARI+SOC & 21 & 42 & $\begin{array}{l}\text { CV and respiratory organ support- } \\
\text { free days OR ( } 95 \% \text { credible interval) }\end{array}$ & Unclear \\
\hline & & SOC & & 402 & $1.76(1.17$ to 2.91$)$ & \\
\hline Canakinumab & CAN-COVID ${ }^{27}$ & CANAK+SOC & 29 & 223 & Patients alive not requiring IMV & Unclear \\
\hline & & $\mathrm{PBO}+\mathrm{SOC}$ & & 222 & $\begin{array}{l}198(89) \\
191(86) p=0.29\end{array}$ & \\
\hline Colchicine & Lopes et $\left.a\right|^{28}$ & $\mathrm{COL}+\mathrm{SOC}$ & 7 & 36 & Need of oxygen therapy & High \\
\hline & & $\mathrm{PBO}+\mathrm{SOC}$ & & 36 & $\begin{array}{l}3(9) \\
15(42)\end{array}$ & \\
\hline & & & & & $\mathrm{RR}(95 \% \mathrm{Cl}) 0.2$ (0.06 to 0.63$)$ & \\
\hline Tofacitinib & Guimarães et $a l^{30}$ & TOFA+SOC & 28 & 144 & Death or respiratory failure & Unclear \\
\hline & & $\mathrm{PBO}+\mathrm{SOC}$ & & 145 & $\begin{array}{l}26(18) \\
42(29)\end{array}$ & \\
\hline & & & & & $\mathrm{RR}(95 \% \mathrm{Cl}) 0.63$ (0.4 to 0.97$)$ & \\
\hline Mavrilimumab & Cremer et $a l^{36}$ & $\mathrm{MAV}+\mathrm{SOC}$ & 60 & 21 & Need of IMV & High \\
\hline & & SOC & & 19 & $\begin{array}{l}5(24) \\
4(21)\end{array}$ & \\
\hline & & & & & $\mathrm{RR}(95 \% \mathrm{Cl}) 1.13$ (0.3 to 3.6$)$ & \\
\hline Interferon beta & Darazan et $a l^{40}$ & IFNbeta1a+SOC & 21 & 20 & IMV & High \\
\hline & & IFNbeta1b+SOC & & 20 & $\begin{array}{l}7(35 \%) \text { in each of the three patient } \\
\text { groups }\end{array}$ & \\
\hline & & SOC & & 20 & & \\
\hline Convalescent plasma & Balcells et $a l^{42}$ & Early $\mathrm{CP}+\mathrm{SOC}$ & 14 & 28 & IMV & High \\
\hline & & Differed/no CP+SOC & & 30 & $\begin{array}{l}5(18) \\
2(7)\end{array}$ & \\
\hline & & & & & $\mathrm{RR}(95 \% \mathrm{Cl}) 3.04$ (0.54 to 17.17$)$ & \\
\hline Non-SARS-CoV-2 IVIG & Raman et $a l^{46}$ & $\mathrm{IVIG}+\mathrm{SOC}$ & 28 & 50 & Days on IMV, mean (SD) & High \\
\hline & & SOC & & 50 & $\begin{array}{l}2.4(0.9) \\
4.5(2.7) p=0.01\end{array}$ & \\
\hline
\end{tabular}

Results from randomised controlled trials in moderate to severe and critical COVID-19.

CANAK, canakinumab; COL, colchicine; CP, convalescent plasma; CQ, chloroquine; CRP, C reactive protein; CV, cardiovascular; HCQ, hydroxychloroquine; IFN, interferon; IMV, invasive mechanical ventilation; IVIG, intravenous immunoglobulins; MAV, mavrilimumab; NIV, non-invasive ventilation; PBO, placebo; RoB, risk of bias; RR, relative risk; SARI, sarilumab; SOC, standard of care; TCZ, tocilizumab; TOFA, tofacitinib.

of patients with $\mathrm{C}$ reactive protein $(\mathrm{CRP})>150 \mathrm{mg} / \mathrm{L} \cdot{ }^{21}$ Among these studies, REMAP-CAP ${ }^{19}(\mathrm{n}=353 \mathrm{TCZ}+\mathrm{SOC}$, $\mathrm{n}=42$ SARI+SOC, n=402 SOC) RECOVERY ${ }^{20} \quad(\mathrm{n}=2094$
TCZ +SOC group and $\mathrm{n}=2022$ in SOC group) and the post hoc analysis of CORIMUNO-TOCI- ${ }^{21}(n=64$ TCZ + SOCand $n=67$ SOC) showed a reduction of death 
at Day 28 (RR 0.82, 95\% CI 0.75 to 0.90), day 21 (RR 0.27, $95 \%$ CI 0.12 to 0.72 ) and day 90 (CORIMUNO-TOCI- 1 in patients with CRP $>150 \mathrm{mg} / \mathrm{L}$ ), respectively (RR $0.64,95 \%$ CI 0.25 to 1.65 ). Of note, in all these studies except the post hoc analysis of CORIMUNO-TOCI- $1,{ }^{21}$ where patients received only oxygen between 3 and $15 \mathrm{~L}$, at baseline the patients were receiving oxygen (26\% to $46 \%)$, NIV (31\% to $48 \%)$ or MV (5\%-30\%). In addition to the efficacy on death, reduction of progression to MV or death at day $21^{20}$ or day $90^{21}$ in CORIMUNOTOCI-1 in patients with CRP $>150 \mathrm{mg} / \mathrm{L}$ or an increase in cardiovascular or respiratory support-free days ${ }^{19}$ were observed. COVACTA ${ }^{18}$ comparing TCZ +SOC $(\mathrm{n}=294)$ to PBO+SOC $(n=144)$ did not show any efficacy on death at day 28 (RR 1.01, 95\% CI 0.7 to 1.5 ) or improvement of clinical outcome (RR $1.01,95 \%$ CI 0.7 to 1.5 ). The study from Soin $e a^{16}$ did not show efficacy on death or disease progression at day 14 or day 28.

Of note, all studies except Soin et al were evaluated at unclear RoB. One study was underpowered and therefore results are not detailed. ${ }^{17}$

The evidence regarding sarilumab is scarcer as the search retrieved two RCTs at unclear RoB; one comparing sarilumab to $\mathrm{SOC},{ }^{19}$ and the other comparing sarilumab to $\mathrm{PBO}^{23}$ The REMAP-CAP trial ${ }^{19}$ included a small arm comparing sarilumab $(\mathrm{n}=44$ patients $)$ to SOC $(\mathrm{n}=402)$; most patients in the sarilumab arm were receiving NIV $(48 \%)$ at baseline. The study showed a reduction in death and $\mathrm{CV}$ and respiratory organ support-free days (RR 1.76, 95\% CI 1.17 to 2.91$).{ }^{18}$ The other RCT ${ }^{23}$ compared two dosages of sarilumab (200 and $400 \mathrm{mg}$ ) to PBO, and showed no efficacy on death (Sari 200: RR 1.13, 95\% CI 0.5 to 2.4; Sari 400 : RR $0.98,95 \%$ CI 0.5 to 2.1 ), progression to MV (Sari 200: RR 1.06, 95\% CI 0.6 to 1.9; Sari 400 : RR 1.2, 95\% CI 0.7 to 2.2) or admission to ICU (Sari 200: RR $0.83,95 \%$ CI 0.3 to 2.1; Sari 400: RR 1.2, $95 \%$ CI 0.5 to 2.7).

Of note, there is a high heterogeneity among trials in terms of the proportion of patients receiving GCs as part of SOC. An important difference was observed between trials starting before and after the positive results of the GC arm of the RECOVERY trial. ${ }^{24}$ It is noteworthy that while in two positive RCTs, a high percentage of patients were receiving GCs (82\% to 93\%), ${ }^{19}{ }^{20}$ in an important negative trial, COVACTA, ${ }^{18}$ which failed to show efficacy in reducing death or improving clinical status, only up to $50 \%$ of patients were receiving GCs. In addition, a recent RCT meta-analysis published in JAMA concluded that TCZ reduced all-cause mortality (OR $0.83,95 \%$ CI 0.72 to 0.94 ) and progression to MV, ECMO or death (OR 0.74, $95 \%$ CI 0.66 to 0.82 ) at day $28 .^{25}$

Of interest, when analysing the subgroup of patients receiving GCs compared with those who did not, death at day 28 was only significantly reduced in the TCZ group receiving GCs (RR 0.77, 95\% CI 0.68 to 0.87 ) p=0.008) but neither in the TCZ group not receiving GCs (RR 1.06, 95\% CI 0.85 to 1.33 ) nor in the SARI group regardless of their GCs status (RR 0.77, 95\% CI 0.64 to $1.31, \mathrm{p}=0.34$ ).
IL-1 inhibitors

As far as anakinra in concerned, only one study at high RoB was retrieved by the search update. This corresponded to a preprint that was subsequently published during the preparation of this manuscript. ${ }^{26}$ This study included patients with COVID-19 pneumonia and soluble urokinase plasminogen activator elevations at $6 \mathrm{ng} / \mathrm{mL}$ or above, which is considered as a predictor of unfavourable outcome. In this population, anakinra $100 \mathrm{mg}$ subcutaneous for 7-10 days increased the number of patients recovered (RR $1.9,95 \%$ CI 1.5 to 2.5), according to the WHO 11-point clinical progression ordinal scale, and decreased mortality at day $28: 3.2 \%$ vs $6.9 \% \quad(\mathrm{HR}=0.45$, $\mathrm{p}=0.045$ ).

Regarding canakinumab, no RCT was retrieved by the search update but while writing this manuscript the CANCOVID study was published ${ }^{27}$ and it demonstrated that the addition of canakinumab to SOC did not provide any benefit on survival at 29 days.

\section{Colchicine}

The SLR identified one small RCT at high RoB. ${ }^{28}$ The study reported that colchicine $0.5 \mathrm{mg}$ three times per day for 5 days followed by $0.5 \mathrm{mg}$ two times per day for 5 days in addition to SOC was able to reduce the duration of hospitalisation and the need of oxygen therapy. However, no significant effect was observed with regard to admission to ICU. In addition, it is important to mention that the colchicine arm of the RECOVERY trial closed in March 2021 since an interim analysis demonstrated no convincing evidence that further recruitment would provide conclusive evidence of benefit in any prespecified subgroup. ${ }^{29}$

\section{JAK inhibitors}

One $\mathrm{RCT}^{30}$ comparing tofacitinib or placebo in addition to SOC reported a significant improvement of the composite outcome of respiratory failure or mortality at day 28 (RR $0.63,95 \%$ CI 0.41 to 0.97 ) in a population where the large majority of patients (about $90 \%$ ) received GCs as part of SOC.

Regarding baricitinib, the SLR retrieved no RCT but important information emerged from the grey literature. The addition of baricitinib to SOC, where the large majority of patients received GC as part of SOC, proved ineffective in improving the composite outcome of progression to NIV/IMV or death by day 28 (OR $0.85,95 \%$ CI 0.67 to $1.08 ; \mathrm{p}=0.18$ ) (COV-BARRIER trial published as a preprint on 3 May 2021 and subsequently published in a peer-reviewed journal while preparing this manuscript). ${ }^{31}$ However, the study found a decrease of 28-day all-cause mortality: $8 \%$ vs $13 \%$ (HR $0.57 ; 95 \%$ CI 0.41 to $0.78 ; \mathrm{p}=0.0018$ ). Finally, with regard to the combination of baricitinib and remdesivir, the Fourth iteration of the Adaptive COVID-19 Treatment Trial (ACTT-4) comparing baricitinib +remdesivir+placebo versus remdesivir +dexamethasone+placebo met predefined futility criteria in an interim analysis hence closed enrolment in 
April 2021. This was announced by a press release and interim data are not available. ${ }^{32}$

A small multiple ascending dose study of the inhaled pan-JAK inhibitor nezulcitinib provided encouraging, although not significant results, on mortality and progression to IMV in hospitalised patients with COVID-19 requiring oxygen therapy and receiving $\mathrm{GC}$ as part of SOC. ${ }^{33}$ Nezulcitinib $3 \mathrm{mg}$ is currently under investigation in a larger trial. ${ }^{34}$ No new RCT data on other JAKs were retrieved but the negative RUXCOVID trial data were published on 21 June 2021 on clinicaltrials.gov website and demonstrated that the addition of ruxolitinib to SOC did not provide any benefit on any clinical outcome at day $28 .^{35}$

\section{GM-CSF inhibitors}

In the previous SLR, no RCTs on granulocytemacrophage colony-stimulating factor (GM-CSF) inhibitors were identified. The update allowed identifying a small RCT investigating mavrilimumab in addition to SOC in hospitalised patients with COVID-19 receiving oxygen therapy or NIV but not IMV. ${ }^{36}$ This study did not provide evidence of efficacy for this treatment strategy but one RCT identified in the grey literature showed a $65 \%$ reduction in risk of IMV/death $(p=0.02)$ and a marked, although not significant, reduction in risk of death with mavrilimumab versus placebo $(p=0.07){ }^{37}$ The search in the grey literature also provided information on another GM-CSF inhibitor, lenzilumab, which was used in addition to SOC in hypoxic hospitalised patients (receiving or not oxygen therapy) was superior to placebo $+\mathrm{SOC}$ in improving survival without ventilation. Of interest, patients with CRP $<150 \mathrm{mg} / \mathrm{L}$ and age $<85$ years were those who had the greatest benefit from lenzilumab. ${ }^{38}$ In addition, a press release reported on the GM-CSF inhibitor otilimab and the data of a preplanned analysis of the OSCAR trial. ${ }^{39}$ Patients aged 70 and over receiving otilimab in addition to SOC had a higher probability of being alive and free of respiratory failure at day 28 compared with those in the same age range receiving placebo in addition to SOC. Furthermore, 60 -day mortality was significantly lower in otilimabtreated patients aged 70 and over.

\section{Type I interferons}

Two small RCTs at high RoB did not observe any benefit after adding interferon beta to SOC. ${ }^{40} 41$

\section{Convalescent plasma and non-SARS-CoV-2 immunoglobulins}

Five RCTs (two at high and two at unclear RoB) were retrieved by the search update and one of them was underpowered. ${ }^{42-45}$ None of the studies showed clear efficacy on mortality or other major clinical outcomes by adding convalescent plasma to SOC. One small RCT at high RoB on the use of non-SARS-CoV-2 immunoglobulins was also retrieved by the search update showed some benefit in reducing hospital or ICU stay. ${ }^{46}$

\section{Anti-SARS CoV-2 monoclonal antibodies}

The new SLR identified one RCT enrolling hospitalised patients with moderate-to-severe COVID-19 and assessing bamlavimab monotherapy. ${ }^{47}$ The study failed to provide any benefit on clinical outcomes (eg, 90-day mortality).

RCT data in patients with mild COVID-19 (non-hospitalised or hospitalised without oxygen therapy)

Two RCTs assessing HCQ in patients with mild to moderate COVID-19 were retrieved(table 3). One was stopped for futility, ${ }^{48}$ while the other one compared two therapeutic strategies: HCQ or favipiravir in a small sample of hospitalised patients ( $\mathrm{n}=50$ in each group) with mild to moderate disease not receiving oxygen supplementation, showing no efficacy on SARS-CoV-2 PCR negativity development or regression of abnormal radiography. ${ }^{49}$ The latter article was retracted while preparing this manuscript. ${ }^{50}$

A large RCT at unclear RoB enrolling non-hospitalised patients with mild COVID-19 demonstrated weak improvement of the composite outcome death or hospitalisation with colchicine. ${ }^{51}$

Two small RCTs, one at high and one at unclear RoB, did not detect any differences following the administration of one dose of PEG-IFN lambda or placebo in non-hospitalised patients with mild COVID-19. ${ }^{52} 53$

Finally, the administration of one dose of PEG IFN- $\alpha 2 b$ instead of placebo in addition to SOC allowed a higher number of hospitalised patients with moderate COVID-19 to achieve clinical improvement on day $15 .{ }^{54}$

As far as mAb against the SARS-CoV-2 spike protein are concerned, the SLR identified three RCTs enrolling nonhospitalised patients with mild to moderate COVID- $19 .^{55-57}$ The combination of bamlanivimab and etesevimab, as well as of casirivimab and imdevimab administrated within the first week after symptom onset was able to significantly reduce viral load. However, casirivimab and imdevimab were effective only in patients seronegative at baseline. Conversely, bamlanivimab monotherapy failed to significantly reduce viral load in non-hospitalised patients. In addition, the results of the antiviral arm of the RECOVERY trial, retrieved in the grey literature, ${ }^{58}$ showed that casirivimab and imdevimab are also able to reduce 28-day mortality in seronegative patients (rate ratio $=0.80,95 \%$ CI 0.70 to 0.91 , $\mathrm{p}=0.0010$ ).

\section{Data from observational studies and case reports}

As summarised in online supplemental table 2 for several compounds, no RCTs were retrieved by the SLR update. Among these, two studies deserve to be commented being the only few of this kind available so far. Two retrospective trials at high of bias compared the efficacy of methylprednisolone (MTP $\geq 1 \mathrm{mg} / \mathrm{kg} /$ day) ${ }^{54}$ or $250-500 \mathrm{mg}$ for $\geq 3$ days) versus dexamethasone (DEXA $\geq 6 \mathrm{mg}$ for $\geq 7$ days). Both studies showed a reduction of death in the group treated with MTP. For the study by Ko et al, ${ }^{59}$ only the subgroup receiving IMV had a lower RR $(0.480,95 \%$ CI 0.235 to $0.956),{ }^{54}$ while in the study from Pinson et $a l^{60}$ the mortality 
Table 3 Effect of immunomodulatory therapies in mild-to-moderate COVID-19. Results from randomized controlled trials.

\begin{tabular}{|c|c|c|c|c|c|c|}
\hline Drug & Author (ref) & $\begin{array}{l}\text { Intervention } \\
\text { comparator(s) }\end{array}$ & $\begin{array}{l}\text { Timepoint } \\
\text { (days) }\end{array}$ & $\mathbf{N}$ treated & Results & RoB \\
\hline Hydroxychloroquine & Dabbous et $a l^{49}$ & $\begin{array}{l}\text { HCQ } \\
\text { Favipiravir }\end{array}$ & 14 & $\begin{array}{l}50 \\
50\end{array}$ & $\begin{array}{l}2 \text { successive negative } \\
\text { SARS-CoV-2 PCR } \\
\text { tests } 48 \text { hours apart RR } \\
(95 \% \mathrm{Cl}) 1.17(0.8 \text { to } 1.7) \\
\text { Radiological } \\
\text { abnormalities RR } \\
(95 \% \mathrm{Cl}) 1.20(0.6 \text { to } 2.5)\end{array}$ & High \\
\hline Colchicine & Tardif et $a l^{51}$ & $\begin{array}{l}\text { COL } \\
\text { PBO }\end{array}$ & 30 & $\begin{array}{l}2235 \\
2253\end{array}$ & $\begin{array}{l}\text { RR }(95 \% \mathrm{Cl}) \\
\text { Death } 0.56(0.19 \text { to } 1.66) \\
\text { Hospitalisation } 0.75 \\
(0.57 \text { to } 0.99) \\
\text { IMV } 0.50(0.23 \text { to } 1.07)\end{array}$ & Unclear \\
\hline PEG-interferon alpha & Pardit et $a l^{54}$ & $\begin{array}{l}\text { PEG-IFN alpha }+ \text { SOC } \\
\text { SOC }\end{array}$ & 15 & $\begin{array}{l}20 \\
20\end{array}$ & $\begin{array}{l}\text { Clinical improvement } \\
\text { (WHO } 7 \text {-point ordinal } \\
\text { scale) } p<0.05\end{array}$ & High \\
\hline PEG-interferon lambda & Jagannathan et $a I^{52}$ & $\begin{array}{l}\text { PEG-IFN lambda-1a } \\
\text { PBO }\end{array}$ & 28 & $\begin{array}{l}60 \\
60\end{array}$ & $\begin{array}{l}\text { Time to cessation of viral } \\
\text { shedding } p=0.29\end{array}$ & Unclear \\
\hline & Feld et $a l^{53}$ & $\begin{array}{l}\text { PEG-IFN lambda-1a } \\
\text { PBO }\end{array}$ & 7 & $\begin{array}{l}30 \\
30\end{array}$ & $\begin{array}{l}\text { Negative RT-PCR, RR } \\
(95 \% \mathrm{Cl}) \\
1.26(0.9 \text { to } 1.7) \\
\text { Improvement of } \\
\text { respiratory symptoms } \\
p=0.06\end{array}$ & High \\
\hline
\end{tabular}

Results from randomised controlled trials.

$\mathrm{COL}$, colchicine; HCQ, hydroxychloroquine; IMV, invasive mechanical ventilation; PBO, placebo; PEG-IFN, pegylated interferon; RoB, risk of bias; RR, relative risk; RT-PCR, real time PCR; SOC, standard of care.

and transfer to ICU were numerically lower, although no statistical tests were presented.

\section{DISCUSSION}

The update of the SLR demonstrated that although a higher number of RCTs is now available assessing new immunomodulatory compounds, a knowledge gap on some therapeutic strategies and on mild-to-moderate COVID-19 still exists and too many low quality/low level of evidence studies are being published. We therefore focused our attention on RCTs and not on observational studies that are still included in the SLR and reported for the sake of comprehensiveness but not discussed in detail in this manuscript.

The new RCTs demonstrated that tocilizumab and some JAK inhibitors, such as baricitinib and tofacitinib, are effective, particularly in association with GC. The role of tocilizumab was unclear based on the results gathered in the previous SLR since there was no strong positive signal in papers published in peer-reviewed journals while the largest positive study, the REMAP-CAP, had only been published as a preprint. The additional data from the tocilizumab arm of the RECOVERY trial, the post hoc analysis of the CORIMUNO-19 TOCI- 1 and the meta-analysis of RCTs published in the JAMA helped clarifying the scenario. Likewise, anti-IL6 receptor antibodies have received a strong recommendation from WHO in patients with severe and critical COVID-19. ${ }^{61}$

As far as JAK inhibitors are concerned, the previous SLR included an article supporting the efficacy of baricitinib in combination with remdesivir and no evidence on tofacitinib was available. In this new SLR, the results from the COV-BARRIER trial with baricitinib and from an independent tofacitinib trial point to a possible JAK inhibition therapeutic application of these compounds, at least in some subgroups of patients (patients on oxygen, including high flow oxygen) but the grey literature pointed to non-efficacy of JAK-2 inhibition. Likewise, selected patients may benefit from other strategies such as convalescent plasma and anti-viral monoclonal antibodies that seem to find a role only in seronegative patients with early disease.

It is important to note that heterogeneity across studies, in terms of outcomes, timepoints and SOC protocols still remains, although to a lesser extent. In particular, after the publication of the results from the GC arm of the RECOVERY trial, GCs were implemented in most SOC protocols and this allowed to better understand the potential of combining them with anti-cytokine molecules in RCTs, although with the limitation of this not being a predefined study arm.

Furthermore, recently published studies may still include patient cohorts enrolled during the first wave and therefore with all the major pitfalls highlighted in our previous SLR. ${ }^{1}$

In conclusion, this SLR informed the EULAR initiative to update the points to consider on the use of immunomodulatory therapies in COVID-19. ${ }^{62}$ Although better evidence is available compared with the previous SLR, the need for RCT with combination therapy (GC +anticytokines) versus monotherapy with GC still remains alongside the need for standardisation of inclusion 
criteria and outcomes to ultimately improve the care and prognosis of affected people.

\section{Author affiliations}

${ }^{1}$ Internal Medicine and Nephrology Unit, Department of Life, Health \& Environmental Sciences, University of L'Aquila, L'Aquila, Italy

${ }^{2}$ Institute of Infection, Immunity and Inflammation, College of Medical Veterinary and Life Sciences, University of Glasgow, Glasgow, UK

${ }^{3}$ Department of Rheumatology, Université Paris-Saclay, Assistance PubliqueHôpitaux de Paris, Hôpital Bicêtre, INSERM UMR1184, Le Kremlin-Bicêtre, France ${ }^{4}$ Leeds Institute of Rheumatic and Musculoskeletal Medicine, University of Leeds \& The NIHR Leeds Biomedical Research Centre, Chapel Allerton Hospital, Leeds, UK ${ }^{5}$ Library \& Evidence Research Centre, Medical Education, Leeds Teaching Hospitals NHS Trust, Leeds UK, Leeds, UK

${ }^{6}$ National Institute for Health Research (NIHR) University College London Hospitals (UCLH) Biomedical Research Centre (BRC), University College London Hospitals (UCLH) NHS Foundation Trust, London, UK

${ }^{7}$ Department of Rheumatology, Northwick Park Hospital, London North West University Healthcare NHS Trust, London, UK

${ }^{8}$ Centre for Rheumatology \& Department of Neuromuscular Diseases,University College London, London, UK

Twitter Aurélie Najm @AurelieRheumo and Pedro M Machado @ pedrommcmachado

Contributors All authors contributed and finally approved the current manuscript. $A A$ and AN equally contributed and are joint first Authors. AA is the guarantor of this work.

Funding This work was funded by the European Alliance of Associations for Rheumatology (EULAR), formerly the European League Against Rheumatism (CLI122). PMM is supported by the National Institute for Health Research (NIHR) University College London Hospitals (UCLH) Biomedical Research Centre (BRC).

Disclaimer The views expressed are those of the authors and not necessarily those of the (UK) National Health Service, NIHR or the Department of Health.

Competing interests $\mathrm{AN}, \mathrm{JE}, \mathrm{LM}$ and GDM have nothing to declare. AA is a member of RMD Open Editorial Board, XM is a member of RMD Open Editorial Board and has received consulting and/or speaker's fees from BMS, Eli Lilly, Galapagos, Gilead, GSK, Janssen, Novartis, Pfizer, Servier and UCB, all unrelated to this manuscript. DMG has received consulting and/or speaker's fees from AbbVie, BMS, Celgene, Eli Lilly, Janssen, MSD, Novartis, Pfizer, Roche and UCB, all unrelated to this manuscript. PMM is a member of RMD Open Editorial Board and has received consulting and/or speaker's fees from AbbVie, BMS, Celgene, Eli Lilly, Galapagos, Janssen, MSD, Novartis, Orphazyme, Pfizer, Roche and UCB, all unrelated to this manuscript.

Patient consent for publication Not applicable.

Provenance and peer review Not commissioned; externally peer reviewed.

Data availability statement No data are available. Not applicable.

Open access This is an open access article distributed in accordance with the Creative Commons Attribution Non Commercial (CC BY-NC 4.0) license, which permits others to distribute, remix, adapt, build upon this work non-commercially, and license their derivative works on different terms, provided the original work is properly cited, appropriate credit is given, any changes made indicated, and the use is non-commercial. See: http://creativecommons.org/licenses/by-nc/4.0/.

ORCID iDs

Alessia Alunno http://orcid.org/0000-0003-1105-5640

Aurélie Najm http://orcid.org/0000-0002-6008-503X

Xavier Mariette http://orcid.org/0000-0002-4244-5417

Gabriele De Marco http://orcid.org/0000-0003-2406-161X

Pedro M Machado http://orcid.org/0000-0002-8411-7972

\section{REFERENCES}

1 Alunno A, Najm A, Mariette X. Immunomodulatory therapies for SARS-CoV-2 infection: a systematic literature review to inform EULAR points to consider. Ann Rheum Dis2021;80.

2 WHO. COVID-19 clinical management: living guidance. Available: https://www.who.int/publications/i/item/WHO-2019-nCoV-clinical2021-1

3 Coronavirus disease 2019 (COVID-19) treatment guidelines. Available: https://www.covid19treatmentguidelines.nih.gov/
4 Ader F, Peiffer-Smadja N, Poissy J, et al. An open-label randomized controlled trial of the effect of lopinavir/ritonavir, lopinavir/ ritonavir plus IFN- $\beta-1 \mathrm{a}$ and hydroxychloroquine in hospitalized patients with COVID-19. Clin Microbiol Infect 2021. doi:10.1016/j. cmi.2021.05.020. [Epub ahead of print: 26 May 2021].

5 Brown SM, Peltan I, Kumar N, et al. Hydroxychloroquine versus azithromycin for hospitalized patients with COVID-19. Results of a randomized, active comparator trial. Ann Am Thorac Soc 2021;18:590-7.

6 Reis G, Moreira Silva EADS, Medeiros Silva DC, et al. Effect of early treatment with hydroxychloroquine or lopinavir and ritonavir on risk of hospitalization among patients with COVID-19: the together randomized clinical trial. JAMA Netw Open 2021;4:e216468.

7 Sivapalan P, Suppli Ulrik C, Sophie Lapperre T, et al. Azithromycin and hydroxychloroquine in hospitalised patients with confirmed COVID-19-a randomised double-blinded placebo-controlled trial. Eur Respir J 2021. doi:10.1183/13993003.00752-2021. [Epub ahead of print: 03 Jun 2021].

8 Schwartz I, Boesen ME, Cerchiaro G, et al. Assessing the efficacy and safety of hydroxychloroquine as outpatient treatment of COVID-19: a randomized controlled trial. CMAJ Open 2021:9:E693-702.

9 Réa-Neto Álvaro, Bernardelli RS, Câmara BMD, et al. An open-label randomized controlled trial evaluating the efficacy of chloroquine/ hydroxychloroquine in severe COVID-19 patients. Sci Rep 2021;11:9023.

10 Barratt-Due A, Olsen IC, Nezvalova-Henriksen K, et al. Evaluation of the Effects of Remdesivir and Hydroxychloroquine on Viral Clearance in COVID-19 : A Randomized Trial. Ann Intern Med 2021:174:1261-9.

11 Galan LEB, Santos NMD, Asato MS, et al. Phase 2 randomized study on chloroquine, hydroxychloroquine or ivermectin in hospitalized patients with severe manifestations of SARS-CoV-2 infection. Pathog Glob Health 2021;115:235-42.

12 Arabi YM, Gordon AC, Derde LPG, et al. Lopinavir-ritonavir and hydroxychloroquine for critically ill patients with COVID-19: REMAP-CAP randomized controlled trial. Intensive Care Med 2021:47:867-86

13 Corral-Gudino L, Bahamonde A, Arnaiz-Revillas F, et al. Methylprednisolone in adults hospitalized with COVID-19 pneumonia. Wien Klin Wochenschr 2021;133:303-11.

14 Tang H-J, Lai C-C. The association between corticosteroid uses and mortality among severe COVID-19 patients. J Infect 2021;82:e24.

15 Jamaati H, Hashemian SM, Farzanegan B, et al. No clinical benefit of high dose corticosteroid administration in patients with COVID-19: a preliminary report of a randomized clinical trial. Eur J Pharmacol 2021;897:173947.

16 Soin AS, Kumar K, Choudhary NS, et al. Tocilizumab plus standard care versus standard care in patients in India with moderate to severe COVID-19-associated cytokine release syndrome (COVINTOC): an open-label, multicentre, randomised, controlled, phase 3 trial. Lancet Respir Med 2021;9:511-21.

17 Wang D, Fu B, Peng Z, et al. Tocilizumab in patients with moderate or severe COVID-19: a randomized, controlled, open-label, multicenter trial. Front Med 2021;15:486-94.

18 Rosas IO, Bräu N, Waters M. Tocilizumab in hospitalized patients with severe Covid-19 pneumonia. N Engl J Med 2021.

19 REMAP-CAP Investigators, Gordon AC, Mouncey PR, et al. Interleukin-6 receptor antagonists in critically ill patients with Covid-19. N Engl J Med 2021;384:1491-502.

20 RECOVERY Collaborative Group. Tocilizumab in patients admitted to hospital with COVID-19 (recovery): a randomised, controlled, openlabel, platform trial. Lancet 2021;397:1637-45.

21 Mariette X, Hermine O, Tharaux P-L, et al. Effectiveness of tocilizumab in patients hospitalized with COVID-19: a follow-up of the CORIMUNO-TOCl-1 randomized clinical trial. JAMA Intern Med 2021:181:1241-1243.

22 Salama C, Han J, Yau L, et al. Tocilizumab in patients hospitalized with Covid-19 pneumonia. N Engl J Med 2021:384:20-30.

23 Lescure F-X, Honda H, Fowler RA, et al. Sarilumab in patients admitted to hospital with severe or critical COVID-19: a randomised, double-blind, placebo-controlled, phase 3 trial. Lancet Respir Med 2021;9:522-32.

24 RECOVERY Collaborative Group. Dexamethasone in hospitalized patients with Covid-19. N Engl J Med 2021;384.

25 WHO Rapid Evidence Appraisal for COVID-19 Therapies (REACT) Working Group, Shankar-Hari M, Vale CL, et al. Association between administration of IL-6 antagonists and mortality among patients hospitalized for COVID-19: a meta-analysis. JAMA 2021;326:499518 
26 Kyriazopoulou E, Poulakou G, Milionis H. Early treatment of COVID-19 with anakinra guided by soluble urokinase plasminogen receptor plasma levels: a double-blind, randomized controlled phase 3 trial. Nat Med 2021.

27 Caricchio R, Abbate A, Gordeev I, et al. Effect of canakinumab vs placebo on survival without invasive mechanical ventilation in patients hospitalized with severe COVID-19: a randomized clinical trial. JAMA 2021;326:230-239.

28 Lopes MI, Bonjorno LP, Giannini MC, et al. Beneficial effects of colchicine for moderate to severe COVID-19: a randomised, doubleblinded, placebo-controlled clinical trial. RMD Open 2021;7.

29 Recovery trial closes recruitment to colchicine treatment for patients hospitalised with COVID-19. Available: https://www.recoverytrial.net/ news/recovery-trial-closes-recruitment-to-colchicine-treatment-forpatients-hospitalised-with-covid-19

30 Guimarães PO, Quirk D, Furtado RH. Tofacitinib in patients hospitalized with Covid-19 pneumonia. N Engl J Med 2021

31 Marconi VC, Ramanan AV, de Bono S, et al. Efficacy and safety of baricitinib for the treatment of hospitalised adults with COVID-19 (COV-BARRIER): a randomised, double-blind, parallel-group, placebo-controlled phase 3 trial. Lancet Respir Med 2021. doi:10.1016/S2213-2600(21)00331-3. [Epub ahead of print: 31 Aug 2021].

32 Statement-NIH closes enrollment in trial comparing COVID-19 treatment regimens. Available: https://www.niaid.nih.gov/newsevents/statement-nih-closes-enrollment-trial-comparing-covid-19treatment-regimens

33 Singh D, Bogus M, Moskalenko V. A phase 2 multiple ascending dose study of the inhaled pan-JAK inhibitor nezulcitinib (TD-0903) in severe COVID-19. Eur Respir J2021.

34 TD-0903 for ali associated with COVID-19. Available: https:// clinicaltrials.gov/ct2/show/NCT04402866

35 Novartis provides update on RUXCOVID study of ruxolitinib for hospitalized patients with COVID-19. Available: https://www. novartis.com/news/media-releases/novartis-provides-updateruxcovid-study-ruxolitinib-hospitalized-patients-covid-19

36 Cremer PC, Abbate A, Hudock K, et al. Mavrilimumab in patients with severe COVID-19 pneumonia and systemic hyperinflammation (MASH-COVID): an investigator initiated, multicentre, doubleblind, randomised, placebo-controlled trial. Lancet Rheumatol 2021;3:e410-e418.

37 Kiniksa Announces positive results for Mavrilimumab phase 2 trial in Non-Mechanically ventilated severe COVID-19 patients. Available: https://www.globenewswire.com/news-release/2021/ 04/12/2208144/0/en/Kiniksa-Announces-Positive-Results-forMavrilimumab-Phase-2-Trial-in-Non-Mechanically-VentilatedSevere-COVID-19-Patients.html

38 Lenzilumab efficacy and safety in newly hospitalized covid-19 subjects: results from the live-air phase 3 randomized double-blind placebo-controlled trial. Available: https://www.medrxiv.org/content/ 10.1101/2021.05.01.21256470v1

39 Gsk announces results evaluating its investigational monoclonal antibody, otilimab, for the treatment of hospitalised adult patients with COVID-19. Available: https://www.gsk.com/en-gb/media/pressreleases/gsk-announces-otilimab-data-for-treatment-of-covid-19/

40 Alavi Darazam I, Shokouhi S, Pourhoseingholi MA, et al. Role of interferon therapy in severe COVID-19: the COVIFERON randomized controlled trial. Sci Rep 2021:11:8059.

41 Khamis F, Al Naabi H, Al Lawati A, et al. Randomized controlled open label trial on the use of favipiravir combined with inhaled interferon beta- $1 \mathrm{~b}$ in hospitalized patients with moderate to severe COVID-19 pneumonia. Int J Infect Dis 2021;102:538-543.

42 Balcells ME, Rojas L, Le Corre N, et al. Early versus deferred anti-SARS-CoV-2 convalescent plasma in patients admitted for COVID-19: a randomized phase II clinical trial. PLoS Med 2021;18:e1003415.
43 Libster R, Pérez Marc G, Wappner D, et al. Early high-titer plasma therapy to prevent severe Covid-19 in older adults. N Engl J Med 2021;384:610-8.

44 Pouladzadeh M, Safdarian M, Eshghi P, et al. A randomized clinical trial evaluating the immunomodulatory effect of convalescent plasma on COVID-19-related cytokine storm. Intern Emerg Med 2021. doi:10.1007/s11739-021-02734-8. [Epub ahead of print: $10 \mathrm{Apr}$ 2021].

45 RECOVERY Collaborative Group. Convalescent plasma in patients admitted to hospital with COVID-19 (recovery): a randomised controlled, open-label, platform trial. Lancet 2021;397:2049-59.

46 Raman RS, Bhagwan Barge V, Anil Kumar D, et al. A phase II safety and efficacy study on prognosis of moderate pneumonia in coronavirus disease 2019 patients with regular intravenous immunoglobulin therapy. J Infect Dis 2021;223:1538-43.

47 A neutralizing monoclonal antibody for hospitalized patients with Covid-19. N Engl J Med 2021;384.

48 Dubée V, Roy P-M, Vielle B, et al. Hydroxychloroquine in mild-tomoderate coronavirus disease 2019: a placebo-controlled double blind trial. Clin Microbiol Infect 2021;27:1124-1130.

49 Dabbous HM, El-Sayed MH, El Assal G, et al. Safety and efficacy of favipiravir versus hydroxychloroquine in management of COVID-19: a randomised controlled trial. Sci Rep 2021;11:7282.

50 Dabbous HM, El-Sayed MH, El Assal G, et al. Retraction note: safety and efficacy of favipiravir versus hydroxychloroquine in management of COVID-19: a randomised controlled trial. Sci Rep 2021;11:18983.

51 Tardif J-C, Bouabdallaoui N, L'Allier PL, et al. Colchicine for community-treated patients with COVID-19 (COLCORONA): a phase 3 , randomised, double-blinded, adaptive, placebo-controlled, multicentre trial. Lancet Respir Med 2021;9:924-32.

52 Jagannathan $\mathrm{P}$, Andrews JR, Bonilla $\mathrm{H}$, et al. Peginterferon Lambda$1 \mathrm{a}$ for treatment of outpatients with uncomplicated COVID-19: a randomized placebo-controlled trial. Nat Commun 2021:12:1967.

53 Feld JJ, Kandel C, Biondi MJ, et al. Peginterferon lambda for the treatment of outpatients with COVID-19: a phase 2, placebocontrolled randomised trial. Lancet Respir Med 2021:9:498-510.

54 Pandit A, Bhalani N, Bhushan BLS, et al. Efficacy and safety of pegylated interferon alfa-2b in moderate COVID-19: a phase II, randomized, controlled, open-label study. Int J Infect Dis 2021;105:516-521.

55 Gottlieb RL, Nirula A, Chen P, et al. Effect of Bamlanivimab as monotherapy or in combination with Etesevimab on viral load in patients with mild to moderate COVID-19: a randomized clinical trial. JAMA 2021;325:632-644.

56 Dougan M, Nirula A, Azizad M, et al. Bamlanivimab plus Etesevimab in mild or moderate Covid-19. N Engl J Med 2021;385:1382-92.

57 Weinreich DM, Sivapalasingam S, Norton T, et al. REGN-COV2, a neutralizing antibody cocktail, in outpatients with Covid-19. N Engl J Med 2021;384:238-251.

58 Casirivimab and imdevimab in patients admitted to hospital with COVID-19 (RECOVERY): a randomised, controlled, open-label, platform trial. Available: https://www.medrxiv.org/content/10.1101/ 2021.06.15.21258542v1

59 Ko JJ, Wu C, Mehta N, et al. A comparison of methylprednisolone and dexamethasone in intensive care patients with COVID-19. J Intensive Care Med 2021;36:673-80.

60 Pinzón MA, Ortiz S, Holguín H, et al. Dexamethasone vs methylprednisolone high dose for Covid-19 pneumonia. PLoS One 2021;16:e0252057.

61 COVID-19 clinical management: living guidance. Available: https:// www.who.int/publications/i/item/WHO-2019-nCoV-clinical-2021-1

62 Alunno A, Najm A, Machado PM, et al. 2021 update of the EULAR points to consider on the use of immunomodulatory therapies in COVID-19. Ann Rheum Dis 2021. doi:10.1136/ annrheumdis-2021-221366. [Epub ahead of print: 07 Oct 2021]. 